\title{
Susceptibility patterns of Staphylococcus aureus biofilms in diabetic foot infections
}

\author{
Carla Mottola ${ }^{1 *}$, Carina S. Matias ${ }^{1}$, João J. Mendes², José Melo-Cristino ${ }^{3}$, Luís Tavares ${ }^{1}$, Patrícia Cavaco-Silva ${ }^{4,5}$ \\ and Manuela Oliveira'
}

\begin{abstract}
Background: Foot infections are a major cause of morbidity in people with diabetes and the most common cause of diabetes-related hospitalization and lower extremity amputation. Staphylococcus aureus is by far the most frequent species isolated from these infections. In particular, methicillin-resistant S. aureus (MRSA) has emerged as a major clinical and epidemiological problem in hospitals. MRSA strains have the ability to be resistant to most $\beta$-lactam antibiotics, but also to a wide range of other antimicrobials, making infections difficult to manage and very costly to treat. To date, there are two fifth-generation cephalosporins generally efficacious against MRSA, ceftaroline and ceftobripole, sharing a similar spectrum.

Biofilm formation is one of the most important virulence traits of $\mathrm{S}$. aureus. Biofilm growth plays an important role during infection by providing defence against several antagonistic mechanisms. In this study, we analysed the antimicrobial susceptibility patterns of biofilm-producing S. aureus strains isolated from diabetic foot infections. The antibiotic minimum inhibitory concentration (MIC) was determined for ten antimicrobial compounds, along with the minimum biofilm inhibitory concentration (MBIC) and minimum biofilm eradication concentration (MBEC), followed by PCR identification of genetic determinants of biofilm production and antimicrobial resistance.
\end{abstract}

Results: Results demonstrate that very high concentrations of the most used antibiotics in treating diabetic foot infections (DFI) are required to inhibit $S$. aureus biofilms in vitro, which may explain why monotherapy with these agents frequently fails to eradicate biofilm infections. In fact, biofilms were resistant to antibiotics at concentrations 10-1000 times greater than the ones required to kill free-living or planktonic cells. The only antibiotics able to inhibit biofilm eradication on $50 \%$ of isolates were ceftaroline and gentamicin.

Conclusions: The results suggest that the antibiotic susceptibility patterns cannot be applied to biofilm established infections. Selection of antimicrobial therapy is a critical step in DFI and should aim at overcoming biofilm disease in order to optimize the outcomes of this complex pathology.

Keywords: Staphylococcus aureus, Diabetic foot infections, MBIC, MBEC, Resistance genes

\section{Background}

Foot infections are a major cause of morbidity in diabetes patients and the most common cause of diabetesrelated hospitalization and lower limb amputation [1]. The physiopathology of diabetic foot infections (DFI) is complex, but its severity and prevalence are a consequence of host-related disorders and pathogens-factors, as virulence and antibiotic resistance traits [1]. DFI are

\footnotetext{
* Correspondence: carlamottola@fmv.ulisboa.pt

'Centro de Investigação Interdisciplinar em Sanidade Animal (CIISA),

Faculdade de Medicina Veterinária, Universidade de Lisboa, Avenida da

Universidade Técnica, 1300-477 Lisbon, Portugal

Full list of author information is available at the end of the article
}

mostly polymicrobial and Staphylococcus aureus is by far the more frequent species involved, either alone or as a component of mixed infections [2, 3].

$S$. aureus is an important nosocomial pathogen that can cause several infections such as: bacteraemia, osteomyelitis, skin infections, pneumonia, meningitis and endocarditis. In particular, MRSA has emerged as a major clinical and epidemiological problem in hospitals since the 1980s [4]. MRSA strains have the ability to resist to all $\beta$-lactam antibiotics and also to a wide range of other antimicrobials, making MRSA infections costly and difficult to manage [5]. Ceftaroline and ceftobiprole 
are, to date, the only anti-MRSA cephalosporins that inhibit PBP2a (penicillin binding protein 2a) at therapeutically concentrations. Ceftobiprole, already evaluated in clinical trials, access the active site of PBP2a by its R2 group, whereas ceftaroline causes an allosteric change in PBP2a [6]. Ceftaroline is FDA approved for treatment of skin and skin structure infections, including those caused by MRSA [6].

Several structural and secreted virulence factors play a role in S. aureus infections, which are multifactorial and depend on bacterial adherence and biofilm formation. In the beginning of an infection, S. aureus produces numerous surface proteins, called "microbial surface components recognizing adhesive matrix molecules" (MSCRAMM) that mediate adherence to host tissues. Once S. aureus adheres to host tissues, it can form biofilms, which enable its persistence by allowing bacteria to evade host defences, impeding access to certain types of immune cells, such as macrophages, which display incomplete penetration into the biofilm matrix and "frustrated phagocytosis" [7]. Additionally, biofilm cells display increased tolerance to antibiotics [8].

In contrast to heritable antibiotic resistance mechanisms, biofilm-associated tolerance is a transient state in which normally susceptible bacteria display an altered physiology that decreases sensitivity. When these cells disperse and re-enter in a planktonic state, they present their normal susceptibility profile [9]. Bacteria embedded within a biofilm are difficult to eradicate due to a wide variation of nutrient gradients that slow or arrest bacterial growth, protein synthesis, and other physiologic activities; bacteria sequestered in biofilms are less susceptible to antibiotics by virtue of their reduced growth rates [10]. Other factors that contribute to biofilm-mediated antimicrobial resistance include inefficient diffusion or sequestering of the agent within biofilm matrix, the presence of "persister" cells and other unknown phenotypic differences [10].

Various genes have been implicated in the onset and maintenance of biofilms by staphylococci. Among these, the most extensively studied are icaA and icaD (intercellular adhesion $\mathrm{A}$ and $\mathrm{B}$ ), products of a gene locus composed by the genes icaR (intercellular adhesion regulator) and ica $A, B, C$, and $D$ (intercellular adhesion $\mathrm{ABCD}$ ), responsible for the synthesis of polysaccharide intercellular adhesin (PIA), which contains $\mathrm{N}$-acetylglucosamine, a major component of the exopolysaccharide matrix that surrounds bacterial cells in the biofilm [11]. Also, the products of pls (plasmin sensitive) which encodes a surface protein, and atl (autolysin) which encodes an autolysin, have been implicated in the formation and structuring of biofilms. The atl is the most predominant peptidoglycan hydrolase in staphylococci, and was also identified as an adhesin involved in primary attachment of cells to polystyrene surfaces [12]. The pls is a homologue of the serine-aspartate repeat ( $\mathrm{Sdr}$ ) surface protein family, of which ClfA (clumping factor A) is the best-characterized member, that reduces adhesion to host proteins and cellular invasiveness [13].

In this study, a collection of $S$. aureus strains isolated from DFI was characterized in terms of their planktonic and biofilm susceptibility patterns, and presence of biofilm and antibiotic resistance genes. The antibiotic minimum inhibitory concentration (MIC) was determined, along with the minimum biofilm inhibitory concentration (MBIC) and minimum biofilm eradication concentration (MBEC), followed by PCR identification of genetic determinants of biofilm production and antimicrobial resistance.

\section{Methods}

\section{Strains}

A total of 53 staphylococci clinical isolates from diabetic foot ulcers (DFU), obtained from 49 samples, were collected in a previous epidemiological survey, as described by Mendes et al. in 2012 [2]. From this collection, twenty-three $(n=23)$ representative biofilm-producing $S$. aureus isolates were selected, based on Pulse Field Gel Electrophoresis (PFGE) and Multilocus Sequence Type (MLST) analysis, previously performed by our research team [14]. A reference strain, S. aureus ATCC 29213, a known biofilm producer, was also included in this study.

\section{Antimicrobial agents}

The antibiotics cefoxitin (FOX), ciprofloxacin (CIP), clindamycin (CLI), doxycycline (DOX), erythromycin (ERY), gentamicin (GEN), linezolid (LZD), meropenem (MEM) and vancomycin (VAN) were obtained from Sigma-Aldrich (Portugal). AstraZeneca (Portugal) generously provided ceftaroline (CPT). All antibiotics were prepared according to CLSI guidelines [15].

\section{Minimum inhibitory concentrations}

MIC were determined for all antibiotics to all strains; etest was performed according to the manufacturer's recommendations (Biomérieux). Test performance was monitored using the reference strain S. aureus ATCC 29213.

\section{Biofilm susceptibility tests}

A modified version of the Calgary Biofilm Pin Lid Device (CBPD) [16] was used to determine the antimicrobial susceptibility of bacteria embedded in a 24-h biofilm, in order to determine the MBIC and $\operatorname{MBEC}[16,17]$. Briefly, a starting inoculum of $5 \times 10^{5} \mathrm{CFU} / \mathrm{mL}$ in Mueller Hinton Broth (MHB, Liofilchem Italy) was distributed in 96-well flat-bottom microtiter plates (Nunc, Roskilde, Denmark), covered with a 96-peg lid (Imuno TSP; Nunc, Roskilde, Denmark) and statically incubated for 24-h at $35{ }^{\circ} \mathrm{C}$, to allow biofilm formation on the pegs $[18,19]$. 
The peg lid was then rinsed three times in $1 \mathrm{X}$ sterile PBS to remove planktonic bacteria, placed on a new plate filled with $200 \mu \mathrm{L}$ of fresh broth containing serial dilutions of antibiotics, from $1024 \mu \mathrm{g} / \mathrm{ml}$ to $0.5 \mu \mathrm{g} / \mathrm{ml}$, and incubated for $24-\mathrm{h}$ at $37{ }^{\circ} \mathrm{C}$ [17-20]. After incubation, the peg lid was removed and the MBIC value was recorded and defined as the last well in which there was no visible growth after incubation $[17,21]$. Next, to determine the MBEC value, the peg lid was rinsed three times in $1 \mathrm{X}$ sterile PBS, placed in a new plate filled with $200 \mu \mathrm{L}$ of fresh MHB and sonicated at 45-60 Hz during $10 \mathrm{~min}[17,22]$, in order to disperse the bacteria from the peg surface. After sonication, the peg lid was discarded and the plate was covered with a normal lid and incubated for $24-\mathrm{h}$ at $37{ }^{\circ} \mathrm{C}$. After incubation, the quantification of biofilm formation was conducted according with a previously described colorimetric microtiter plate, using Alamar Blue [23]. Briefly, $5 \mu$ l of resazurin (Alamar Blue, AB, ThermoScientific, Spain) was added to the wells and the plates were incubated for one hour at $37^{\circ}$ C. After incubation, absorbance (A) values at $570 \mathrm{~nm}$ and $600 \mathrm{~nm}$ were recorded in a microplate reader (BMG LABTECH GmbH, Germany). Controls included media plus Alamar Blue (control one) and bacterial cells plus media plus $A B$ without antibiotic (control two). The MBEC was defined as the lowest drug concentration resulting in $\leq 1 / 2$ the absorbance value when compared to control two. Assays were performed at least twice and the average absorbance values used to determine the MBEC values.

\section{PCR screening of biofilm associated and antibiotic resistance genes}

All strains were investigated to detect the presence of genes associated with biofilm formation, namely: icaA, icaD, atl and pls. Genes associated with antibiotic resistance were also screened, namely: blaZ (penicillin resistance); $m e c A$ and $m e c C$ (oxacillin resistance); tet $K$, tet $L$, tet $M$ and tet $O$ (tetracycline resistance); $m s r A$, $\operatorname{erm} A$, $\operatorname{erm} B$ and ermC (erythromycin resistance); aac $\left(6^{\prime}\right)$ $\operatorname{aph}\left(2^{\prime \prime}\right)$ (gentamicin resistance) and norA (ciprofloxacin resistance).

Detection of mecA gene and its homologous $m e c C$ were performed by multiplex PCR [24]. Oligonucleotide primer sequences are described in Table 1 . All amplification reactions were prepared with a mixture containing: $12.5 \mu \mathrm{l}$ of Supreme NZYTaq 2x Green Master Mix (NZYTech, Portugal), $1 \mu \mathrm{l}$ of each primer (forward and reverse) (STABVIDA Lda, Portugal) and $5.5 \mu \mathrm{l}$ of sterile water (water for molecular biology, NZYTech, Portugal). To this mixture, $1 \mu \mathrm{l}$ of the previous extracted DNA was added, resulting in a total reaction volume of $25 \mu \mathrm{l}$. PCR amplification was performed in a thermal cycler (MyCycler Thermal Cycler, Bio-Rad, Portugal) using conditions described in the
Table 1 PCR target genes and primers used in this work

\begin{tabular}{|c|c|c|}
\hline \multirow[t]{2}{*}{ Gene } & Primer & \multirow[t]{2}{*}{ Reference } \\
\hline & Sequence $\left(5^{\prime} \rightarrow 3^{\prime}\right)$ & \\
\hline \multirow[t]{2}{*}{$i c a A$} & TCTCTTGCAGGAGCAATCAA & \multirow[t]{2}{*}{ Arciola et al. (2001) [46] } \\
\hline & AGGCACTAACATCCAGCA & \\
\hline \multirow[t]{2}{*}{$i c a D$} & ATGGTCAAGCCCAGACAGAG & \multirow[t]{2}{*}{ Arciola et al. (2001) [46] } \\
\hline & CGTGTITCAACATTTAATGCAA & \\
\hline \multirow[t]{2}{*}{ atl } & CTTCAGCACAACCAAGATC & \multirow[t]{2}{*}{ Petrelli et al. (2008) [4] } \\
\hline & GGTTACCGACTGCACCGTCAC & \\
\hline \multirow[t]{2}{*}{ pls } & GTAATACAACAGGAGCAGATGG & \multirow[t]{2}{*}{ Petrelli et al. (2008) [4] } \\
\hline & GTAGCTITCCATGTITTCCTG & \\
\hline \multirow[t]{2}{*}{ blaz } & ACTTCAACACCTGCTGCTITC & \multirow[t]{2}{*}{ Martineau et al. (2000) [38] } \\
\hline & TGACCACTITTATCAGCAACC & \\
\hline \multirow[t]{2}{*}{$\operatorname{mec} A$} & TCCAGATTACAACTTCACCAGG & \multirow[t]{2}{*}{ Stegger et al. (2012) [24] } \\
\hline & CCACTTCATATCTTGTAACG & \\
\hline \multirow[t]{2}{*}{ mecC } & GAAAAAAAGGCTTAGAACGCCTC & \multirow[t]{2}{*}{ Stegger et al. (2012) [24] } \\
\hline & GAAGATCTITCCGTITCAGC & \\
\hline \multirow[t]{2}{*}{ tetK } & TCGATAGGAACAGCAGTA & \multirow[t]{2}{*}{ Ng et al. (2001) [47] } \\
\hline & CAGCAGATCCTACTCCTT & \\
\hline \multirow[t]{2}{*}{ tetl } & TCGTTAGCGTGCTGTCATTC & \multirow[t]{2}{*}{ Ng et al. (2001) [47] } \\
\hline & GTATCCCACCAATGTAGCCG & \\
\hline \multirow[t]{2}{*}{ tetM } & GTGGACAAAGGTACAACGAG & \multirow[t]{2}{*}{ Ng et al. (2001) [47] } \\
\hline & CGGTAAAGTTCGTCACACAC & \\
\hline \multirow[t]{2}{*}{ tetO } & AACTTAGGCATTCTGGCTCAC & \multirow[t]{2}{*}{ Ng et al. (2001) [47] } \\
\hline & TCCCACTGTTCCATATCGTCA & \\
\hline \multirow[t]{2}{*}{$m s r A$} & TCCAATCATTGCACAAAATC & \multirow[t]{2}{*}{ Martineau et al. (2000) [38] } \\
\hline & AATTCCCTCTATTTGGTGGT & \\
\hline \multirow[t]{2}{*}{ ermA } & TATCTTATCGTTGAGAAGGGATT & \multirow[t]{2}{*}{ Martineau et al. (2000) [38] } \\
\hline & CTACACTTGGCTTAGGATGAAA & \\
\hline \multirow[t]{2}{*}{ ermB } & СTATCTGATTGTTGAAGAAGGATT & \multirow[t]{2}{*}{ Martineau et al. (2000) [38] } \\
\hline & GTTACTCTTGGTIAGGATGAAA & \\
\hline ermC & CTTGTTGATCACGATAATITCC & Martineau et al. (2000) [38] \\
\hline & ATCTITAGCAAACCCGTATTC & \\
\hline $\operatorname{aac}\left(6^{\prime}\right)-\operatorname{aph}\left(2^{\prime \prime}\right)$ & TTGGGAAGATGAAGTाITAGA & Martineau et al. (2000) [38] \\
\hline & CCTITACTCCAATAATTGGCT & \\
\hline norA & TTCACCAAGCCATCAAAAAG & Pourmand et al. (2014) [48] \\
\hline & CTTGCCTITCTCCAGCAATA & \\
\hline
\end{tabular}

references reported in Table 1 . Positive controls for the tested genes were gently provided by: Dr. Mark Holmes (University of Cambridge, England), Dr. Penadés (Cardenal Herrera University, Valencia, Spain) and Dr. Birgit Strommenger (Robert Koch Institute, Berlin, Germany).

\section{Results}

Minimum inhibitory concentrations

All isolates were considered susceptible to vancomycin, linezolid and doxycycline, with $\mathrm{MIC}$ values $\leq 1 \mu \mathrm{g} / \mathrm{ml}$, $\leq 4 \mu \mathrm{g} / \mathrm{ml}$ and $\leq 0.5 \mu \mathrm{g} / \mathrm{ml}$ respectively. Ceftaroline MIC 
values were $\leq 0.5 \mu \mathrm{g} / \mathrm{ml}$ and only two isolates presented $\mathrm{MIC} \geq 4 \mu \mathrm{g} / \mathrm{ml}$ (ceftaroline-resistant). All isolates, except for one, originated MIC values for clindamycin of $\leq 0.5$ $\mu \mathrm{g} / \mathrm{ml}$. Gentamicin MIC values were $\leq 1 \mu \mathrm{g} / \mathrm{ml}$, except for three resistant isolates. About $57 \%$ of isolates were considered susceptible to ciprofloxacin with MIC $\leq 2 \mu \mathrm{g} /$ $\mathrm{ml}$, and $65 \%$ were erythromycin susceptible with MIC $\leq 0.5 \mu \mathrm{g} / \mathrm{ml}$. Eight isolates (35\%) were cefoxitinresistant, with MIC values $\geq 8 \mu \mathrm{g} / \mathrm{ml}$ (Tables 2 and 3 ).

\section{Biofilm susceptibility tests}

MBIC and MBEC concentration values are summarized in Table 2. For MRSA isolates, cefoxitin MBIC concentrations ranged from two to five dilutions higher than MIC values, reaching values of 256 to $1024 \mu \mathrm{g} / \mathrm{ml}$, while MBEC values were even higher (from 2 to $\geq 1024 \mu \mathrm{g} / \mathrm{ml}$ ). Instead, for methicillin-susceptible $S$. aureus (MSSA) isolates MBIC and MBEC values for cefoxitin were the same as MIC values, with the exception of four isolates, for which MBIC and MBEC values were two times higher when compared to MIC. In $65 \%$ of the isolates $(n=15)$, MBIC and MBEC values for linezolid were the same, and one thousand times higher when compared with MIC values (Fig. 1).

Other antibiotics originated different results. All MBIC and $M B E C$ values were much higher than the respective MIC values, and MBEC values were at least twice higher than the MBIC ones. Ceftaroline MBIC values were four to sixteen times higher than MIC values, ranging from 0.5 to $8 \mu \mathrm{g} / \mathrm{ml}$, except for one MRSA isolate that reached $1024 \mu \mathrm{g} / \mathrm{ml}$; and the MBEC concentrations reached $1024 \mu \mathrm{g} / \mathrm{ml}$, including four of the eight MRSA isolates. Regarding ciprofloxacin, MBIC values achieved an average of eight times higher compared with MIC, ranging from 0.5 to $512 \mu \mathrm{g} / \mathrm{ml}$, except one isolate that reached $1024 \mu \mathrm{g} / \mathrm{ml}$; for all isolates, except for two, MBEC values increased from 256 to $512 \mu \mathrm{g} / \mathrm{ml}$. Similar results were obtained for clindamycin, but the gap between the MIC and MBIC values was higher, with MIC of 0.03 to MBIC of $0.5-128 \mu \mathrm{g} / \mathrm{ml}$, except for one isolate that reached a MBIC value of $1024 \mu \mathrm{g} / \mathrm{ml}$. MBIC values for doxycycline were even higher, as half of the isolates reached a MBIC concentration of 0.5 to $2 \mu \mathrm{g} / \mathrm{ml}$, three hundreds to one thousand times higher than MIC. The other half showed MBIC values of 32 to $512 \mu \mathrm{g} / \mathrm{ml}$, one thousand times higher than the respective MIC. Doxycycline MBEC values ranged from 64 to $128 \mu \mathrm{g} / \mathrm{ml}$ (Fig. 1).

The biofilm inhibition concentrations for erythromycin increased about four times in comparison with the values for MIC, from $0.12->256 \mu \mathrm{g} / \mathrm{ml}$ to 0.5 $>256 \mu \mathrm{g} / \mathrm{ml}$. For MRSA, MIC and MBIC values were the same and equal to $>256 \mu \mathrm{g} / \mathrm{ml}$. These isolates reached MBEC concentrations of $64->1024 \mu \mathrm{g} / \mathrm{ml}$, representing an increase of five hundred to one thousand times compared with MIC and MBIC values (except for the resistant isolates). In the case of gentamicin, it was observed an increase from MIC to MBIC of two to five hundred times higher, reaching values of $0.5->128 \mu \mathrm{g} / \mathrm{ml}$ (except for one MRSA isolate, that showed MBIC value of $1024 \mu \mathrm{g} / \mathrm{ml}$ ); MBEC reached $256 \mu \mathrm{g} / \mathrm{ml}$ (including six of the eight MRSA isolates). Meropenem and vancomycin produced the major increase regarding MBEC values, being one thousand times higher than the value of MIC, and five hundred times higher than the MBIC values $(0.5$ to $>1024 \mu \mathrm{g} / \mathrm{ml}$ and 8 to $>1024 \mu \mathrm{g} / \mathrm{ml}$ for meropenem and vancomycin, respectively). The MBIC values ranged from 0.5 to $32 \mu \mathrm{g} / \mathrm{ml}$ for meropenem and from 1 to $16 \mu \mathrm{g} / \mathrm{ml}$ for vancomycin, except for one isolate that reached $1024 \mu \mathrm{g} / \mathrm{ml}$ (Fig. 1).

\section{PCR screening of biofilm associated and antibiotic resistance genes}

All isolates were positive for the biofilm associated genes $i c a A$, icaD and $a t l$, and negative for pls. Eight isolates (35\%) were MRSA harbouring the $m e c A$ gene and were resistant to cefoxitin. None of the isolates presented the $m e c C$ gene. Three isolates presented the blaZ gene, one of which was MRSA and resistant to six of the antibiotics tested (Table 3 ).

Regarding the tet genes, none of the isolates were positive for tet $L$ and tet $O$, one MRSA isolate was positive for tet $M$ (and also blaZ positive), and tet $K$ was found in three MSSA isolates. With the exception for two isolates, the erythromycin-resistant isolates were positive for erm genes, namely six for ermA (five MRSA and one MSSA) and three for ermC (two MRSA and one MSSA); contrariwise, none of these isolates was positive for $\mathrm{ermB}$ and $m s r A$ genes. The $\operatorname{aac}\left(6^{\prime}\right)-\operatorname{aph}\left(2^{\prime \prime}\right)$ gene was found in three isolates, one MRSA and two MSSA. Nineteen

Table 2 In vitro MIC, MBIC and MBEC values for the antibiotics tested against S. aureus DFU isolates $\left({ }^{*} \mathrm{CLSI}\right.$ range susceptibility)

\begin{tabular}{lllllllllll}
\hline & \multicolumn{1}{l}{ Antimicrobial agents } & \multicolumn{1}{l}{} & & & & \\
\cline { 2 - 10 } & FOX & CPT & CIP & CLI & DOX & ERY & GEN & LZD & MEM & VAN \\
\hline MIC range & $1.5-256$ & $0.064-38$ & $0.06->32$ & $0.015-0.06$ & $0.064-0.125$ & $0.12->256$ & $0.06-64$ & $1-2$ & $0.015-16$ & $0.25-1$ \\
MBIC range & $2-256$ & $0.5-8$ & $0.5-512$ & $0.5-128$ & $0.5-512$ & $0.5->256$ & $0.5->128$ & $1->1024$ & $0.5-32$ & $1-16$ \\
MBEC range & $2-1024$ & $0.5-1024$ & $256-512$ & $64->1024$ & $64-128$ & $64->1024$ & $1->256$ & $4->1024$ & $0.5->1024$ & $8->1024$
\end{tabular}

FOX, cefoxitin $\left(\leq 4 \mu \mathrm{g} / \mathrm{ml}^{*}\right)$; CPT, ceftaroline $\left(\leq 0.5 \mu \mathrm{g} / \mathrm{ml}^{*}\right)$; CIP, ciprofloxacin $\left(\leq 4 \mu \mathrm{g} / \mathrm{ml}^{*}\right) ;$ CLI, clindamycin $\left.(\leq 0.25 \mu \mathrm{g} / \mathrm{ml})^{*}\right) ; \mathrm{DOX}, \mathrm{doxycycline}\left(\leq 4 \mu \mathrm{g} / \mathrm{ml}{ }^{*}\right) ; \mathrm{ERY}$, erythromycin $\left(\leq 8 \mu \mathrm{g} / \mathrm{ml}^{*}\right) ; \mathrm{GEN}$, gentamicin $\left(\leq 4 \mu \mathrm{g} / \mathrm{ml}^{*}\right) ;$ LZD, linezolid $\left.(\leq 4 \mu \mathrm{g} / \mathrm{ml})^{*}\right) ;$ MEM, meropenem $\left(\leq 4 \mu \mathrm{g} / \mathrm{ml}^{*}\right) ; \operatorname{VAN}, \operatorname{vancomycin}\left(\leq 2 \mu \mathrm{g} / \mathrm{ml}^{*}\right)$ 
Table 3 Antibiotic resistance phenotypes and genotypes of S. aureus DFU isolates

\begin{tabular}{|c|c|c|c|c|c|c|c|c|c|c|c|c|c|c|c|c|c|c|c|c|c|c|c|}
\hline \multirow[t]{3}{*}{ Isolate } & \multicolumn{23}{|c|}{ Resistance } \\
\hline & \multicolumn{10}{|c|}{ Phenotype } & \multicolumn{13}{|c|}{ Gene } \\
\hline & FOX & CIP & CPT & CLI & DOX & ERY & GEN & LZD & MEM & VAN & \multirow{2}{*}{ blaz } & \multirow{2}{*}{$\frac{\text { mecA }}{+}$} & \multirow{2}{*}{ mecC } & \multirow{2}{*}{$\begin{array}{l}\text { ermA } \\
+\end{array}$} & \multirow{2}{*}{ ermB } & \multirow{2}{*}{ ermC } & \multirow{2}{*}{$\begin{array}{l}m s r A \\
-\end{array}$} & \multirow{2}{*}{$\begin{array}{l}\text { norA } \\
+\end{array}$} & \multirow{2}{*}{ tetK } & \multirow{2}{*}{ tetL } & \multirow{2}{*}{ tetM } & \multirow{2}{*}{ tetO } & $\operatorname{aac}\left(6^{\prime}\right)-\operatorname{aph}\left(2^{\prime \prime}\right.$ \\
\hline 101 & $R$ & $\mathrm{R}$ & S & S & S & S & S & S & I & S & & & & & & & & & & & & & + \\
\hline 102 & S & R & R & S & S & S & S & S & S & S & - & - & - & - & - & - & - & + & - & - & - & - & - \\
\hline 103 & S & S & S & s & s & S & S & S & S & S & - & - & - & - & - & - & - & + & - & - & - & - & - \\
\hline 104 & S & S & S & S & S & S & S & S & s & S & - & - & - & - & - & + & - & + & - & - & - & - & - \\
\hline 105 & S & S & S & S & S & S & S & S & S & S & - & - & - & - & - & - & - & + & - & - & - & - & - \\
\hline 106 & R & $\mathrm{R}$ & S & S & s & R & s & S & s & S & - & + & - & + & - & - & - & + & - & - & - & - & - \\
\hline 107 & R & $\mathrm{R}$ & S & $R$ & S & $R$ & R & S & R & S & + & + & - & - & - & - & - & + & - & - & + & - & - \\
\hline 108 & $R$ & $\mathrm{R}$ & $R$ & $S$ & $S$ & $\mathrm{R}$ & $S$ & $S$ & I & $S$ & - & + & - & - & - & + & - & - & - & - & - & - & - \\
\hline 109 & $\mathrm{R}$ & $\mathrm{R}$ & $S$ & $S$ & $S$ & $R$ & $S$ & $S$ & $\mathrm{R}$ & $S$ & - & + & - & - & - & + & - & - & - & - & - & - & - \\
\hline 110 & S & $\mathrm{R}$ & $S$ & S & $S$ & $R$ & $S$ & S & $\mathrm{R}$ & S & - & - & - & + & - & - & - & + & - & - & - & - & - \\
\hline 111 & $S$ & $S$ & $S$ & $S$ & $S$ & $S$ & $S$ & $S$ & $S$ & $S$ & - & - & - & - & - & - & - & + & - & - & - & - & - \\
\hline 112 & $S$ & $S$ & $S$ & $S$ & $S$ & $S$ & $S$ & $S$ & $S$ & $S$ & + & - & - & - & - & - & - & + & - & - & - & - & - \\
\hline 113 & S & I & $S$ & $S$ & $S$ & $S$ & $\mathrm{R}$ & $S$ & S & S & - & - & - & - & - & - & - & + & + & - & - & - & + \\
\hline 114 & $S$ & $S$ & $S$ & S & $S$ & $S$ & $R$ & $S$ & S & $S$ & + & - & - & - & - & - & - & + & + & - & - & - & + \\
\hline 115 & $\mathrm{R}$ & $\mathrm{R}$ & $S$ & $S$ & $S$ & $R$ & $S$ & $S$ & $S$ & $S$ & - & + & - & + & - & - & - & + & - & - & - & - & - \\
\hline I16 & $S$ & $S$ & $S$ & S & S & $S$ & S & S & S & $S$ & - & - & - & - & - & - & - & - & + & - & - & - & - \\
\hline 117 & $\mathrm{R}$ & $\mathrm{R}$ & $S$ & $S$ & $S$ & $\mathrm{R}$ & $S$ & $S$ & $S$ & $S$ & - & + & - & + & - & - & - & + & - & - & - & - & - \\
\hline 118 & $\mathrm{R}$ & $\mathrm{R}$ & $S$ & $S$ & $S$ & $\mathrm{R}$ & $S$ & $S$ & $S$ & $S$ & - & + & - & + & - & - & - & + & - & - & - & - & - \\
\hline 119 & S & $S$ & S & S & S & S & S & S & $S$ & $S$ & - & - & - & - & - & - & - & - & - & - & - & - & - \\
\hline 120 & $S$ & $S$ & $S$ & $S$ & $S$ & $S$ & $S$ & $S$ & S & $S$ & - & - & - & - & - & - & - & + & - & - & - & - & - \\
\hline 121 & S & $S$ & S & S & S & $S$ & $S$ & $S$ & $S$ & $S$ & - & - & - & - & - & - & - & + & - & - & - & - & - \\
\hline 122 & $S$ & $S$ & $S$ & $S$ & $S$ & $S$ & $S$ & $S$ & $S$ & $S$ & - & - & - & - & - & - & - & + & - & - & - & - & - \\
\hline 123 & $S$ & $S$ & S & $S$ & $S$ & $S$ & $S$ & $S$ & $S$ & $S$ & - & - & - & - & - & - & - & + & - & - & - & - & - \\
\hline
\end{tabular}

$R$, resistant; $S$, susceptible; I, intermediate; +, positive in specific PCR; -, negative in specific PCR. FOX, cefoxitin; CIP, ciprofloxacin; CPT, ceftaroline; DOX, doxycycline; ERY, erythromycin; GEN, gentamicin; LZD, linezolid; MEM, meropenem; VAN, vancomycin. blaZ, penicillin resistance; mecA and mecC, oxacillin resistance; ermA, ermB, ermC and $m s r A$, erythromycin resistance; norA, ciprofloxacin resistance; tetK, tetL, tetM and tetO, tetracycline resistance; $\operatorname{aac}\left(6^{\prime}\right)$-aph(2)", gentamicin resistance

isolates $(82 \%)$ presented the norA gene, six of which were MRSA and thirteen were MSSA (Table 3).

\section{Discussion}

The diversity of bacterial populations in chronic wounds, such as diabetic foot ulcers, and the biofilm mode of growth of the infecting organisms, may be important contributors to the chronicity of wounds [25]. As expected, all isolates carried the genes icaA, icaD and atl, due to their virulence profile and ability to form biofilm. None of the isolates were positive for $p l s$ gene, and this may suggest the adhesion and cellular invasiveness properties of the studied isolates, considering that the MRSA surface protein $p l s$ reduces these virulence features $[13,26]$.

Biofilm formation, as widely described in literature, represents a big obstacle for the clinical efficacy of antibiotics, and the results of antimicrobial susceptibility testing cannot be directly applied to bacterial biofilm infections, due to higher probability of failure [27]. Biofilm can resist even to antibiotic concentrations 10-10.000 times higher than the ones needed to kill planktonic cells [10]. In this study, antibiotic concentrations required to inhibit or eradicate biofilm were much higher than the respective MIC values and should not be clinically applied. Furthermore, MBEC values were often several times higher than MBIC values.

Although all MRSA isolates should be considered as resistant to $\beta$-lactams in vivo [15], almost all isolates were susceptible to meropenem. MBIC values for this antibiotic were thirty to one thousand times higher than MIC, being still in the range of susceptibility, however meropenem was unable to eradicate biofilm. The results suggested that cefoxitin is able to inhibit and eradicate $S$. aureus biofilms formed by MSSA isolates.

PCR amplification of $m e c A$ is considered the "gold standard" technique for detection of methicillin resistance among S. aureus [28]. However, the discovery of a 


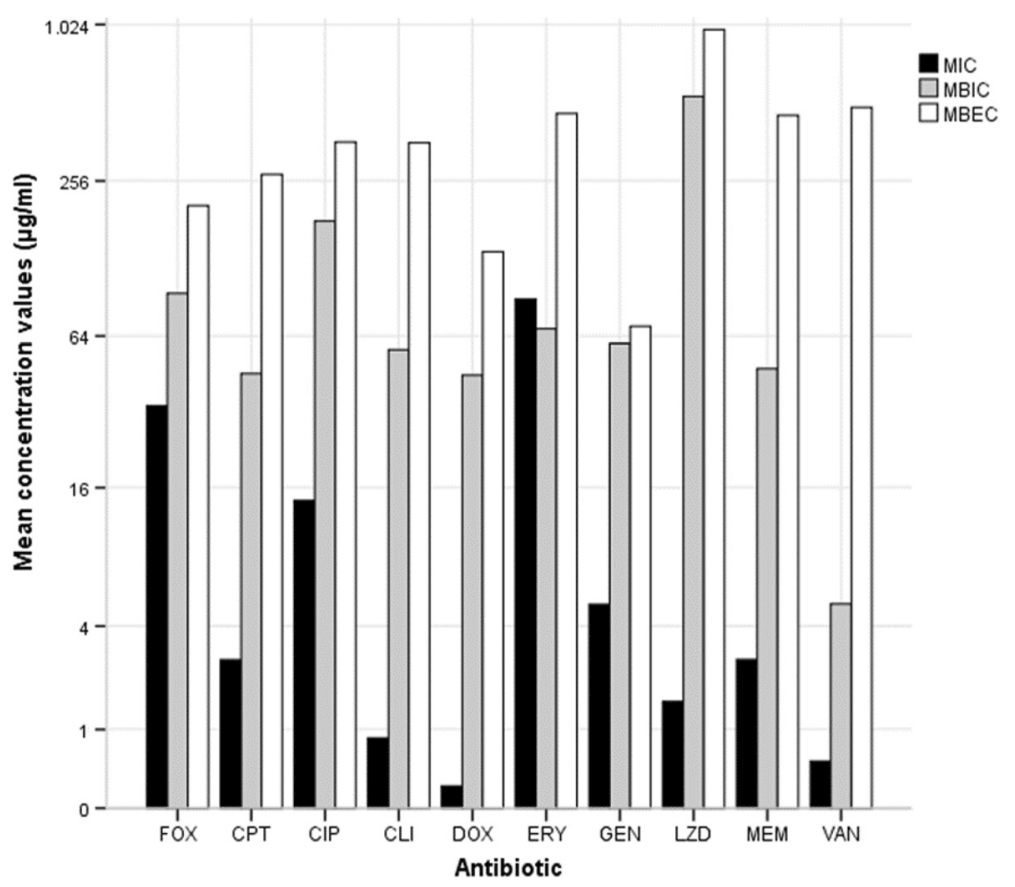

Fig. 1 Minimum inhibitory concentration (MIC), minimum biofilm inhibitory concentration (MBIC) and minimum biofilm eradication concentration (MBEC) of S. aureus DFU isolates as determined by a modified version of the Calgary Biofilm Pin Lid Device. FOX, cefoxitin; CIP, ciprofloxacin; CPT, ceftaroline; DOX, doxycycline; ERY, erythromycin; GEN, gentamicin; LZD, linezolid; MEM, meropenem; VAN, vancomycin

new mecA homologous gene, $m e c C$, determined the need to establish new detection protocols [24], although normally the screening of the homologous gene is only performed in oxacillin-resistant $m e c A$ negative isolates [29]. In this study, a multiplex assay was applied for the screening of mecA and $m e c C$ in all isolates, being possible to detect the mecA gene in $35 \%$ of the $S$. aureus DFU isolates $(n=8)$. By the contrary, $\operatorname{mec} C$ was not detected in any isolates, which is not surprising because MRSA isolates harbouring $m e c C$ are currently rare, and have only been reported in 13 European countries to date, not including Portugal [30]. The presence of mecA positive strains among the study isolates can be associated with the increasing prevalence of antibiotic-resistant bacteria in DFU isolates, particularly MRSA, as described by Bowling et al. [31]. Also, Djahmi et al. suggested that MRSA prevalence may be related with the increase of antimicrobial treatment required, considering the high frequency of recurrent ulcers [32]. Nowadays, penicillin resistance is present in about $90 \%$ of human $S$. aureus isolates. Two mechanisms are involved: the production of $\beta$-lactamases encoded by the bla $Z$ gene and an altered penicillin-binding protein, PBP2a, encoded by $\operatorname{mec} A[33,34]$. In our study, only three isolates were positive for blaZ. This may be due to the primers used, because multiple polymorphisms within the blaZ gene have already been identified and the results can vary when different regions of the gene are targeted [34], or may also be due to the fact that the isolates express penicillin resistance encoded by $m e c A$.

Antibiotic susceptibility tests showed that gentamicin and ceftaroline were the most potent agents against $S$. aureus biofilms, reaching clinical concentrations that can be applied to inhibit and eradicate biofilms. This was observed even for the MRSA isolates, since ceftaroline and gentamicin were effective in inhibiting biofilm production by seven of the eight MRSA isolates, while ceftaroline was effective in eradicating biofilm production by half of the MRSA isolates and gentamicin was effective in eradicating biofilm production by two isolates MRSA isolates. Today ceftaroline represents a good alternative to treat infections by $S$. aureus with reduced susceptibility to current agents, as recent studies have proven its efficacy against biofilm, applied alone or in combination $[35,36]$.

In 1999, Ceri et al. [16] already described the efficacy of gentamicin against $S$. aureus biofilms, as well as other studies that followed [20,37]. The $\operatorname{aac}\left(6^{\prime}\right)$-aph $\left(2^{\prime \prime}\right)$ is the gene coding for the most frequently encountered aminoglycoside modifying enzyme (AME) in Gram-positive bacteria, which inactivates a broad range of clinically useful aminoglycosides, especially gentamicin and tobramycin; this enzyme is bifunctional because it catalyses both acetyltransferase and phosphotransferase reactions [38]. The $\operatorname{aac}\left(6^{\prime}\right)-\operatorname{aph}\left(2^{\prime \prime}\right)$ gene was found in three isolates, one MRSA and two MSSA, with no discrepant 
results with the resistance phenotypes obtained by etest. These findings are in agreement with other studies, which reported that all aminoglycoside-resistant strains carried the $\operatorname{aac}\left(6^{\prime}\right)$-aph(2") gene [38].

Linezolid lacked activity against staphylococci biofilms because it didn't inhibit or eradicate biofilms, as already reported in other studies [18, 20,39]. Clindamycin, doxycycline and vancomycin were effective against planktonic cultures and inhibited biofilm produced by most isolates; however, these antibiotics showed no ability to eradicate biofilms. This may suggest that these agents, although effective against bacteria in suspensions, may not be the most suitable antibiotics for treating biofilm related infections. Previous studies have shown that these antibiotics lack activity against staphylococci grown in biofilms [17-19, 39, 40].

Although isolates presented a high rate of resistance to ciprofloxacin and erythromycin, their MBIC concentrations were about eight times higher than MIC values but were still clinically adequate. They were not able to eradicate biofilm, as previously described for ciprofloxacin in other studies $[16,18]$. Several genes are implicated in erythromycin resistance, especially in staphylococci and streptococci. The gene ermA is located on the transposon Tn554 and has a single specific site for insertion into $S$. aureus chromosome; the $\mathrm{ermB}$ gene is located on the transposon Tn551 of a penicillinase plasmid; the ermC gene is generally located on small plasmids and is responsible for constitutive or inducible resistance to erythromycin [38]. Staphylococcal strains resistant to macrolides and type-B streptogramins also frequently harbor $m s r A$, which encodes an ATP-dependent efflux pump [38]. In this study, ermA was found in five resistant and one sensible erythromycin staphylococci. Regarding $\mathrm{erm} C$, this gene was less frequently found than ermA, namely in two resistant and one sensible erythromycin staphylococci. These results are according to previous reports, in which ermA was the most prevalent erm-gene followed by ermC [38, 41, 42]. The discrepance between the erythromycin susceptible isolates and their erm positivity was already described [38]. Numerous factors could explain the sensitive phenotype in these strains, including regulation of erm genes and absence of host factors associated with the expression of erythromycin resistance. These factors can also explain the cefoxitin-susceptible $S$. aureus isolates carrying the $m e c A$ gene.

The increasing prevalence of MRSA has led to a new interest in the usage of macrolide-lincosamidestreptogramin B $\left(\mathrm{MLS}_{\mathrm{B}}\right)$ antibiotics to treat $S$. aureus infections, with clindamycin being the preferred agent due to its excellent pharmacokinetics. However, this increased application promoted a raise in resistance to $\mathrm{MLS}_{\mathrm{B}}$ antibiotics. Clindamycin resistance is commonly caused by a one target site modification mediated by erm genes, difficult to detect in vitro, as they appear erythromycin resistant and clindamycin sensitive [43].

Tetracycline resistance determinants are widespread among bacterial species, consisting in active efflux pumps that result from acquisition of plasmid-located genes, tet $K$ and tet $L$, and in ribosomal protection mediated by transposon or chromosomal located genes tet $M$ or tetO [30,42]. MRSA isolates typically show tet $M$ or tet $K M$ genotype; tet $K$ is the most frequent genotype found in $S$. aureus, followed by tetM [39, 43, 44]. The same was observed in this study, in which three MSSA isolates were tet $K$ positive and one MRSA was tet $M$ positive; tet $L$ and tet $O$ were not found. Tet-positive isolates were sensible to doxycycline. In tet $K$ positive isolates, this gene confers high resistance to tetracycline, oxytatracycline, chlortetracycline but low resistance to monocycline, 6-demethyl-6-deoxytetracycline and doxycycline [44]. Surprisingly, the only tet $M$ positive isolate was doxycycline sensible. Since this gene is believed to confer resistance to all drugs of tetracycline group [45], it may be suggested that prevalence of resistance to tetracyclines in S. aureus is underestimated or, as demonstrated by Trzcinski et al. [45], recognition of tetracycline resistance in $S$. aureus strains often depends on the different interpretation guidelines used.

In recent years, an increase in fluoroquinolone resistance in S. aureus, including MIC strains, has been spreading worldwide. Resistance mechanisms to these antibiotics involve mutations within the $\operatorname{gyr} A$ and $\operatorname{gyr} B$ genes, which encode for subunits of DNA gyrase, an established target of fluoroquinolones; analogous mutations in $g r l A$ and $g r l B$, which encode for subunits of DNA topoisomerase IV; and the increased expression of the norA gene, which encodes for a drug efflux protein, $n o r A$, and mutations in the norA coding region $[45,46]$. Nor $A$ is a membrane protein which actively transports norfloxacin and other hydrophilic fluoroquinolones out of the bacterial cell, thus effectively decreasing the intracellular concentration of the drugs [45]. Nineteen isolates were positive for norA gene but eleven of them were susceptible to ciprofloxacin.

From a clinical perspective, the discrepancy between genotype and phenotypic resistance expression suggest that a susceptible strain harbouring, but not expressing, an antibiotic resistance gene should be regarded as potentially resistant to that antibiotic. Overall, we did not detect a significant presence of antibiotic resistance genes, compared to the great biofilm resistance of the isolates, even when using high antimicrobial concentrations.

\section{Conclusions}

To our knowledge, this is the first study on antibiotic susceptibility tests targeting biofilm-producing $S$. aureus 
isolates from diabetic foot infections. It was found that only very high concentrations of the most used antibiotics in DFU were capable to inhibit $S$. aureus biofilms in vitro, which may explain why monotherapeutics frequently fail to eradicate biofilm infections. Biofilms were resistant to antibiotics concentrations 10 to 1000 times higher than the concentrations needed to kill free-living or planktonic cells. This high level of resistance in biofilms makes chronic infections, like DFI, extremely difficult to eradicate using conventional antimicrobial therapy.

MIC values were not always predictive of the MBIC and MBEC values. Only gentamicin and ceftaroline proved to be effective in eradicating biofilms, formed by half of isolates at clinical drug concentrations, while the other tested drugs were only able to inhibit adherent cells. In particular, ceftaroline showed a very good potential for inhibiting and eradicating biofilms produced by MRSA isolates. It is clear that antibiotic susceptibility values for planktonic populations are not necessarily applicable to effective treatment of infections by the same organism, once a biofilm has been established. These differences may be an important factor in the selection of antimicrobial therapy for most of DFI, to whom $S$. aureus is the main virulent organism involved, rendering important the investigation of antibiotic susceptibility of biofilm infections.

\section{Abbreviations \\ atl, autolysin; DFI, diabetic foot infections; DFU, diabetic foot ulcers; icaA, intercellular adhesion $A$; icaD, intercellular adhesion $D$; icaR, intercellular adhesion regulator; $\mathrm{MBEC}$, minimum biofilm eradication concentration; MBIC, minimum biofilm inhibitory concentration; MIC, minimum inhibitory concentration; MRSA, methicillin-resistant S. aureus; MSSA, methicillin-susceptible S. aureus; PBP2a, penicillin binding protein 2a; pls, plasmin sensitive}

\section{Acknowledgements}

We thank the AstraZeneca, for providing the ceftaroline antibiotic used in this work.

\section{Funding}

The study was conducted by the financial support of "This study was conducted by the financial support of CIISA ("Centro de Investigação Interdisciplinar em Sanidade Animal"), Faculty of Veterinary Medicine, University of Lisbon, Portugal - Project UID/CVT/00276/2013 and FCT Project PTDC/SAU-MIC/122816/2010-"Biofilms in diabetic foot: microbial virulence characterization and cross-talk of major isolates" (both funded by Foundation for Science and Technology - FCT, Portugal). Carla Mottola holds a PhD fellowship (SFRH/BD/72872/2010) from FCT, Portugal. The funding bodies did not play any role in the design of the study, in the collection, analysis and interpretation of data or in writing the manuscript.

\section{Availability of data and materials}

The data set(s) supporting the results of this article is (are) included within the article (and its additional file(s)).

\section{Authors' contributions}

$\mathrm{CM}$ and $\mathrm{MO}$ conceived and designed the experiments. CM and CSM performed the experiments. $\mathrm{CM}$ analysed the data and wrote the manuscript. JJ contributed to the samples collection. MO contributed reagents, materials, and analysis tools and helped with the writing of the manuscript. JJ, CSM, PCS, LT, and JMC contributed to data interpretation and helped with the writing of the manuscript. All authors read and approved of the final manuscript.

\section{Competing interests}

The authors declare that they have no competing interests.

\section{Consent for publication}

Not applicable.

Ethics approval and consent to participate

Not applicable.

\section{Author details}

${ }^{1}$ Centro de Investigação Interdisciplinar em Sanidade Animal (CIISA), Faculdade de Medicina Veterinária, Universidade de Lisboa, Avenida da Universidade Técnica, 1300-477 Lisbon, Portugal. ${ }^{2}$ Departamento de Medicina Interna, Hospital de Santa Marta/Centro Hospitalar de Lisboa Central, EPE, Lisbon, Portugal. ${ }^{3}$ Faculdade de Medicina, Universidade de Lisboa, Instituto de Microbiologia, Lisbon, Portugal. ${ }^{4}$ TechnoPhage, S.A. Lisbon, Portugal. ${ }^{5}$ Centro de Investigação Interdisciplinar Egas Moniz (CiiEM), Instituto Superior de Ciências da Saúde Egas Moniz, Monte de Caparica, Portugal.

Received: 3 January 2016 Accepted: 8 June 2016

Published online: 23 June 2016

\section{References}

1. Spichler A, Hurwitz BL, Armstrong DG, Lipsky BA. Microbiology of diabetic foot infections: from Louis Pasteur to "crime scene investigation.". BMC Med. 2015;13:1-13.

2. Mendes JJ, Marques-Costa A, Vilela C, Neves J, Candeias N, Cavaco-Silva P, et al. Clinical and bacteriological survey of diabetic foot infections in Lisbon. Diabetes Res Clin Pract. 2012;95:153-61.

3. Lipsky BA, Richard J-L, Lavigne J-P. Diabetic foot ulcer microbiome: one small step for molecular microbiology ... One giant leap for understanding diabetic foot ulcers? Diabetes. 2013;62:679-81.

4. Petrelli D, Repetto A, D'Ercole S, Rombini S, Ripa S, Prenna M, et al. Analysis of meticillin-susceptible and meticillin-resistant biofilm-forming Staphylococcus aureus from catheter infections isolated in a large Italian hospital. J Med Microbiol. 2008;57:364-72.

5. Rice LB. Antimicrobial resistance in gram-positive bacteria. Am J Infect Control. 2006;119:11-9.

6. Chan LC, Basuino L, Diep B, Hamilton S, Chatterjee SS, Chambers HF. Ceftobiprole- and ceftaroline-resistant methicillin-resistant Staphylococcus aureus. Antimicrob Agents Chemother. 2015;59:2960-3.

7. Scherr TD, Heim CE, Morrison JM, Kielian T. Hiding in Plain Sight: Interplay between Staphylococcal Biofilms and Host Immunity. Front Immunol. 2014; $5: 1-7$

8. Gordon RJ, Lowy FD. Pathogenesis of methicillin-resistant Staphylococcus aureus infection. Clin Infect Dis. 2008;46 Suppl 5:S350-9.

9. Lister JL, Horswill AR. Staphylococcus aureus biofilms: recent developments in biofilm dispersal. Front Cell Infect Microbiol. 2014;4:178.

10. Kaplan JB. Antibiotic-induced biofilm formation. Int J Artif Organs. 2011;34: 737-51

11. Rohde H, Burandt EC, Siemssen N, Frommelt L, Burdelski C, Wurster S, et al. Polysaccharide intercellular adhesin or protein factors in biofilm accumulation of Staphylococcus epidermidis and Staphylococcus aureus isolated from prosthetic hip and knee joint infections. Biomaterials. 2007;28: $1711-20$.

12. Biswas R, Voggu L, Simon UK, Hentschel P, Thumm G, Götz F. Activity of the major staphylococcal autolysin Atl. FEMS Microbiol Lett. 2006;259:260-8.

13. Hussain M, Schäfer D, Juuti KM, Peters G, Haslinger-Löffler B, Kuusela PI, et al. Expression of Pls (plasmin sensitive) in Staphylococcus aureus negative for pls reduces adherence and cellular invasion and acts by steric hindrance. $J$ Infect Dis. 2009;200:107-17.

14. Mottola C, Semedo-Lemsadeck T, Mendes JJ, Melo Cristino J, Cavaco Silva P, Tavares L, Oliveira M: Molecular typing, virulence traits and antimicrobial resistance of diabetic foot staphylococci. J Biomed Sci. 2016;23:33.

15. Clinical and Laboratory Standards Institute: M100-S23 Performance Standards for Antimicrobial Susceptibility Testing; Twenty-Third Informational Supplement. 2013(January)

16. Ceri H, Olson M, Stremick C. The Calgary Biofilm Device: new technology for rapid determination of antibiotic susceptibilities of bacterial biofilms. J Clin Microbiol. 1999 
17. LaPlante KL, Mermel LA. In vitro activities of telavancin and vancomycin against biofilm-producing Staphylococcus aureus, S. epidermidis, and Enterococcus faecalis strains. Antimicrob Agents Chemother. 2009;53:3166-9.

18. Pettit RK, Weber CA, Kean MJ, Hoffmann H, Pettit GR, Tan R, et al. Microplate Alamar blue assay for Staphylococcus epidermidis biofilm susceptibility testing. Antimicrob Agents. 2005;49:2612-7.

19. Cafiso V, Bertuccio T, Spina D, Purrello S, Stefani S. Tigecycline inhibition of a mature biofilm in clinical isolates of Staphylococcus aureus: comparison with other drugs. FEMS Immunol Med Microbiol. 2010;59:466-9.

20. Coraça-Huber DC, Fille M, Hausdorfer J, Pfaller K, Nogler M. Staphylococcus aureus biofilm formation and antibiotic susceptibility tests on polystyrene and metal surfaces. J Appl Microbiol. 2012;112:1235-43.

21. Pettit RK, Weber CA, Pettit GR. Application of a high throughput Alamar blue biofilm susceptibility assay to Staphylococcus aureus biofilms. Ann Clin Microbiol Antimicrob. 2009:8:28

22. Harrison JJ. Stremick C a, Turner RJ, Allan ND, Olson ME, Ceri H: Microtiter susceptibility testing of microbes growing on peg lids: a miniaturized biofilm model for high-throughput screening. Nat Protoc. 2010;5:1236-54.

23. Mottola C, Mendes JJ, Cristino JM, Cavaco-Silva P, Tavares L, Oliveira M. Polymicrobial biofilms by diabetic foot clinical isolates. Folia Microbiol (Praha). 2015;61 Suppl 1:35-43.

24. Stegger M, Andersen PS, Kearns A, Pichon B, Holmes MA, Edwards G, et al. Rapid detection, differentiation and typing of methicillin-resistant Staphylococcus aureus harbouring either mecA or the new mecA homologue mecA LGA251. Clin Microbiol Infect. 2012;18:395-400.

25. Neut D. Tijdens-Creusen EJ a, Bulstra SK, van der Mei HC, Busscher HJ: Biofilms in chronic diabetic foot ulcers-a study of 2 cases. Acta Orthop. 2011:82:383-5.

26. Savolainen K, Paulin L, Westerlund-wikstrom B, Foster T, Korhonen TK, Kuusela P. Expression of pls, a Gene Closely Associated with the mecA Gene of Methicillin-Resistant Staphylococcus aureus, Prevents Bacterial Adhesion In Vitro. Microbiology. 2001;69:3013-20.

27. Patel R. Biofilms and Antimicrobial Resistance. Clin Orthop Relat Res. 2005: 437:41-7.

28. Siripornmongcolchai T, Chomvarin C, Chaicumpar K, Limpaiboon T, Wongkhum C. Evaluation of different primers for detecting mecA gene by PCR in comparison with phenotypic methods for discrimination of methicillin-resistant Staphylococcus aureus. Southeast Asian J ournal Trop Med Public Heal. 2002;33:758-63.

29. García-Álvarez L, Holden MTG, Lindsay H, Webb CR, Brown DFJ, Curran MD, et al. Meticillin-resistant Staphylococcus aureus with a novel mecA homologue in human and bovine populations in the UK and Denmark: A descriptive study. Lancet Infect Dis. 2011;11:595-603.

30. Paterson GK, Harrison EM. Holmes M a.: The emergence of mecC methicillin-resistant Staphylococcus aureus. Trends Microbiol. 2014;22:42-7.

31. Bowling FL, Jude EB, Boulton AJM. MRSA and diabetic foot wounds: contaminating or infecting organisms? Curr Diab Rep. 2009;9:440-4.

32. Djahmi N, Messad N, Nedjai S, Moussaoui A, Mazouz D, Richard J, et al. Molecular epidemiology of Staphylococcus aureus strains isolated from inpatients with infected diabetic foot ulcers in an Algerian University Hospital. Clin Microbiol Infect. 2013;19:E398-404.

33. Pereira LA, Harnett GB, Hodge MM, Cattell JA, Speers DJ. Real-time PCR assay for detection of blaZ genes in Staphylococcus aureus clinical isolates. J Clin Microbiol. 2014;52:1259-61.

34. El Feghaly RE, Stamm JE. Fritz $S$ a., Burnham CAD: Presence of the blaZ beta-lactamase gene in isolates of Staphylococcus aureus that appear penicillin susceptible by conventional phenotypic methods. Diagn Microbiol Infect Dis. 2012;74:388-93.

35. Barber KE, Smith JR, Ireland CE, Boles BR, Rose WE, Rybak MJ: Evaluation of Ceftaroline Alone and in Combination Against Biofilm-producing 1 Methicillin-resistant Staphylococcus aureus (MRSA) with Reduced Susceptibility to 2 daptomycin and vancomycin in an In Vitro Pharmacokinetic/Pharmacodynamic Model. Antimicrob Agents Chemother 2015(May).

36. Barber KE, Werth BJ, McRoberts JP, Rybak MJ. A Novel Approach Utilizing Biofilm Time Kill Curves in Assessing the Bactericidal Activity of Ceftaroline Combinations Against Biofilm Producing Methicillin-Resistant Staphylococcus aureus (MRSA). Antimicrob Agents Chemother. 2014;58:2989-92.

37. Kotulová D, Slobodníková L. Susceptibility of Staphylococcus aureus biofilms to vancomycin, gemtamicin and rifampin. Epidemiol Mikrobiol Imunol. 2010;59:80-7.
38. Martineau F, Picard FJ, Lansac N, Ménard C, Roy PH, Ouellette M, et al. Correlation between the resistance genotype determined by multiplex PCR assays and the antibiotic susceptibility patterns of Staphylococcus aureus and Staphylococcus epidermidis. Antimicrob Agents Chemother. 2000;44: 231-8.

39. Smith K, Perez A, Ramage G, Gemmell CG, Lang S. Comparison of biofilmassociated cell survival following in vitro exposure of meticillin-resistant Staphylococcus aureus biofilms to the antibiotics clindamycin, daptomycin, linezolid, tigecycline and vancomycin. Int J Antimicrob Agents. 2009;33:374-8.

40. Rose WE, Poppens PT. Impact of biofilm on the in vitro activity of vancomycin alone and in combination with tigecycline and rifampicin against Staphylococcus aureus. J Antimicrob Chemother. 2009;63:485-8.

41. Strommenger B, Kettlitz C, Werner G. Multiplex PCR assay for simultaneous detection of nine clinically relevant antibiotic resistance genes in Staphylococcus aureus. J Clin Microbiol. 2003;41:4089-94.

42. Werner G, Cuny C, Schmitz F. Staphylococcus aureus with Reduced Sensitivity to Glycopeptides. J Clin Microbiol. 2001;39:3586-90.

43. Jv S, Janakiram K, Vijaya D. Inducible clindamycin resistance in Staphylococcus aureus : Reason for treatment failure. J Int Med Dent. 2015; 2:97-103.

44. Andersen JL, He GX, Kakarla P, Ranjana KC, Kumar S, Lakra WS, et al. Multidrug efflux pumps from enterobacteriaceae, Vibrio cholerae and Staphylococcus aureus bacterial food pathogens. Int J Environ Res Public Health. 2015;12:1487-547.

45. Trzcinski K, Cooper BS, Hryniewicz W, Dowson CG. Expression of resistance to tetracyclines in strains of methicillin-resistant Staphylococcus aureus. J Antimicrob Chemother. 2000;45:763-70.

46. Arciola $C R$, Baldassarri L, Montanaro L. Presence of icaA and icaD genes and slime production in a collection of staphylococcal strains from catheterassociated infections. J Clin Microbiol. 2001;39:2151-6.

47. Ng LK, Martin I, Alfa M, Mulvey M. Multiplex PCR for the detection of tetracycline resistant genes. Mol Cell Probes. 2001;15:209-15.

48. Pourmand MR, Yousefi M, Salami SA, Amini M. Evaluation of Expression of NorA Efflux Pump in Ciprofloxacin Resistant Staphylococcus aureus against Hexahydroquinoline Derivative by Real-Time PCR. Acta Med Iran. 2014;52: 424-9.

\section{Submit your next manuscript to BioMed Central and we will help you at every step:}

- We accept pre-submission inquiries

- Our selector tool helps you to find the most relevant journal

- We provide round the clock customer support

- Convenient online submission

- Thorough peer review

- Inclusion in PubMed and all major indexing services

- Maximum visibility for your research

Submit your manuscript at www.biomedcentral.com/submit
Biomed Central 